\title{
Equilibrium in women with osteoporosis submitted to balance training with and without an oscillating vibratory pole
}

\author{
Juliana Rodrigues Soares Ruzene, MSc ${ }^{a, *}$, \\ Mary Hellen Morcelli, MSc ${ }^{a}$, Marcelo Tavella Navega, PhD ${ }^{\text {b,c }}$ \\ a Instituto de Biociências, Unesp, Rio Claro, São Paulo, Brazil \\ b Physical and Occupational Therapy Department Unesp, Marília, São Paulo, Brazil \\ c Post-Graduate Program in Human Development and Technologies, Instituto de Biociências, Unesp, Rio \\ Claro, São Paulo, Brazil
}

Received 24 January 2015; received in revised form 5 March 2015; accepted 13 March 2015

\section{KEYWORDS}

Elderly;

Fall accidents;

Postural balance

\begin{abstract}
Summary Objectives: An eight-week balance training program, with and without oscillation of vibratory pole, was shown to have a medium-term persistence effect on the performance of elderly physically-active women with osteoporosis.

Methods: The 29 women who completed the study were randomly separated into two groups: an Oscillating Pole Group (OPG; $69.6 \pm 5.8$ years; $n=14$ ) and a Non-Oscillating Pole Group (NPG; $70.9 \pm 7.4$ years; $n=15$ ). The improvement in equilibrium was evaluated using the Berg Balance Scale before training, after training and in the Follow-Up (eight-weeks after the conclusion of the training).

Results and discussion: The NPG presented both Post-Training ( $\mathrm{p}=.018$ relative to pretraining) and Follow-Up ( $p=.007$ ) improvements in equilibrium. The improvement for OPG was near significant ( $\mathrm{p}=.051$ relative to pre-training) in Post-Training and significant $(p=.038)$ in the Follow-Up. There were no significant differences between Post-Training and Post-Follow-Up ( $\mathrm{p}=.999)$ for either group or in the intergroup comparisons (no statistically-significant effect of oscillation of the pole).

(c) 2015 Elsevier Ltd. All rights reserved.
\end{abstract}

\footnotetext{
* Corresponding author. Rua Bandeirantes, 156, apartamento 8 - Centro, CEP: 17501-090, Marília, São Paulo, Brazil. Tel.: +55 143413 8822.

E-mail address: juliana_ruzene@yahoo.com.br (J.R.S. Ruzene).
} 


\section{Introduction}

Aging leads to functional and structural modifications in the organism. The changes associated with chronic degenerative diseases, among them osteoporosis, make the elderly population vulnerable to physical-functional deterioration (Meuleman et al., 2000; Faria et al., 2003). Osteoporosis is currently one of the most common diseases among the elderly and in 2001 was characterized by the Osteoporosis Consensus as "the 21st century epidemic" (National Institutes of Health (2001)).

Worldwide, approximately $30 \%$ of women and $10 \%$ of men over 50 years of age are affected by osteoporosis. In the United States, osteoporosis affects $55 \%$ of the population in this age group (Schröder et al., 2012; Meneses et al., 2012) and in Brazil it has been estimated that 10 million people suffer from this disease (Souza et al., 2012). The main consequence of osteoporosis is the occurrence of fractures and their ensuing complications. Among fractures, the most compromising is that of the femur, which is associated with the increase in mortality and morbidity (Randell et al., 2000; Navega et al., 2008). Approximately 80-90\% of the hip fractures in the elderly are due to falls and represent about $45 \%$ of the cases of death among these individuals (Arnold et al., 2008). The predisposition to suffer low impact fractures caused by osteoporosis makes it a particularly aggravating risk factor for the elderly, in particular for those with problems of equilibrium or balance (Pinheiro et al., 2010).

The practice of regular physical exercise by women with osteoporosis has been identified as an important factor for increasing the quality of life. Appropriate exercise has been shown to improve bone mineral density in the lumbar spine and hips, reduce lower back pain, increase the force of the handgrip, and improve equilibrium, leading to a reduction of nearly $36 \%$ in the risk of an accidental fall. (Schröder et al., 2012; Costa et al., 2012; Lirani-Galvão and Lazaretti-Castro, 2010). Regular physical exercise is therefore of utmost importance for improving balance in women with osteoporosis (Arnold et al., 2008), since any reduction in the frequency of falls and fractures will have the effect of decreasing the morbidity and mortality rates among osteoporotic elderly (Lirani-Galvão and LazarettiCastro, 2010; Madureira et al., 2007).

The effects of vibration on the human body are well documented, but only recently has vibration been used as a means of perfecting physical capacity training (Torvinen et al., 2002; Delecluse et al., 2003; Verschueren et al., 2004; Cormie et al., 2006; Roelants et al., 2006; Bogaerts et al., 2007; Rees et al., 2008). The vibratory pole is an exercise tool (1520-mm length, $719 \mathrm{~g}$ weight); its constituents are a flexible fiberglass pole with a rubber handle $(17.9-\mathrm{cm}$ girth) in the middle and weighted rubber at each end (Mileva et al., 2010). Training with a vibratory pole is distinct from other trainings due to the low frequency employed, about $5 \mathrm{~Hz}$, and by the passive behavior of the pole, whose vibrations produced trunk muscle contraction (Anders et al., 2008). The vibrations of the body, transmitted via the pole, produce cyclical disturbances, demanding muscle activity to stabilize and maintain the equilibrium of the body (Gonçalves et al., 2011). During the exercises with the oscillatory pole, inertial transformations occur in addition to external resistance, thus making the maintenance of balance more difficult (Hallal et al., 2010).

In spite of numerous studies indicating that physical activity programs involving resistance exercises, aerobic activity and muscle stretching are beneficial for women with osteoporosis, no studies were found in the literature analyzing the effect of balance training with a vibratory pole in women with osteoporosis when they were submitted to balance tests. The purpose of this study was thus to verify the effect of an eight-week long balance training with and without oscillation of the vibratory pole on the equilibrium of elderly women with osteoporosis. The working hypothesis was that both the groups should present improvement in their balance, with the expectation that the performance of the group submitted to the oscillation of the vibratory pole might potentially be better.

\section{Methods}

This study was approved by the Local Independent Ethics Committee (IRB) (CEP-2011-66) and all the volunteers signed an informed consent form.

\section{Individuals}

A total of 29 elderly women with osteoporosis, between 60 and 80 years of age, completed this study. None of the participants were institutionalized; all were without pain, fracture, or severe injury to soft tissues within the six month period prior to the study. None presented neurological, cardiovascular or respiratory disorders and none scored under 20 points on the Mini Mental State Examination (MMSE) (Almeida and Crocco, 2000).

All were classified as physically active according to the International Physical Activity Questionnaire (IPAQ) (Craig et al., 2003). The volunteers also needed to have performed at least one Bone Densitometry Examination in the previous 12 months that diagnosed lumbar spine osteoporosis, that is, with a T-Score under or equal to $-2,5$ Standard Deviations (SD) (Meneses et al., 2012).

\section{Procedures}

The volunteers were divided randomly into two groups: the Oscillating Pole Group (OPG; $69.6 \pm 5.8$ years of age; $n=14$ ) composed of elderly women that performed the training with the oscillating vibratory pole (Flexibar ${ }^{\circledR}$ ) and the Non-Oscillating Pole Group (NPG; $70.9 \pm 7.4$ years of age; $n=15$ ) composed of elderly women that performed the training without the oscillation of the same pole $\left(\right.$ Flexibar $\left.^{\circledR}\right)$. During the initial evaluation, the tests performed were the Berg Balance Scale, the Mini Mental State Examination and the characterization of physical activity level (IPAQ). The volunteers were required to execute a minimum of $75 \%$ of the training sessions as the criterion for continuing to participate in the study. Fig. 1 shows the samples eliminated from the study due to absence from more than $25 \%$ of the training sessions. 


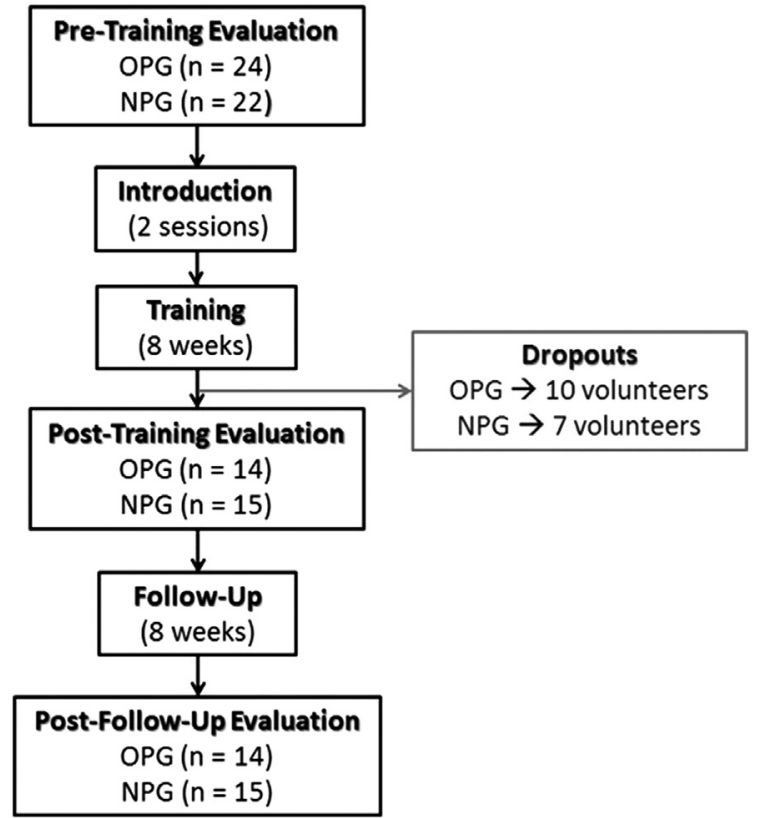

Figure 1 Flow diagram of the data collection routine. The Pre-training Evaluation data for the dropouts were not included in the statistical analyses.

We emphasize that the whole training protocols applied and all evaluations performed in this study were implemented by a single researcher; and it was a blind experiment, in which both groups had no knowledge of what was happening to them and to the other group during the evaluations and training however, the tester was well aware.

Like Hallal et al. (2010), responsible for developing the training procedure adopted in the present research, we opted to perform our study only with physically active women, in order to eliminate the possibility that any improvement in equilibrium that the volunteers might present after training could be attributed simply to the onset of physical activity rather than to the balance training procedure performed by them.

\section{Physical activity level}

The International Physical Activity Questionnaire (IPAQ) was used in order to classify the volunteers' level of physical exercise. The questionnaire's objective is to measure the physical activity performed during the week with regard to work, leisure, transport and housework (Benedetti et al., 2004). Only elderly women classified as "highly active" and "active" according to this questionnaire were included in the study.

\section{Berg Balance Scale}

The Berg Balance Scale was used for the evaluation of balance. This scale provides a detailed point system for predicting the risk of falls by the elderly. The BBS consists of 14 chores that represent daily life activities. The score for each of the 14 chores is graded from zero (unable to perform the chore) to four (able to perform the chore independently) on five items for each chore. A sum of points or overall score from 56 to 54 points indicates the absence of a risk of falls; from 53 to 46 points indicates a low to moderate risk of falls and, under 46 points, a high risk of falls (Myiamoto et al., 2004; Shumway-Cook and Woolacott, 2003). The Berg Balance Scale was applied by a single examiner in all the evaluations performed. The general instructions recommended by the protocol were carried out and, if the volunteer did not understand the instructions provided for the execution of a given activity, it was demonstrated to her.

\section{Training program}

The training programs for both OPG and NPG were started one week after the initial evaluation and only one of the study's researchers was responsible for the instruction of volunteers from both groups. Each group performed the suggested activities based on a specific protocol consisting of 21 exercises with a progressive level of difficulty during an eight consecutive week period, with two thirty-minute sessions weekly (Fig. 1).

Before initiating the training, two sessions were held to introduce the vibratory poles to the volunteers. The actual training began only after all the volunteers were able to perform correctly the oscillation of the vibratory pole. The movement of the oscillating pole was performed by flexion and extension of the elbows. After the eight-week training period, the Berg Balance Scale was applied again (PostTraining evaluation); after a subsequent eight-week period of follow-up, the evaluation was repeated (Post-follow-up evaluation).

\section{Training protocol}

The training protocol (Fig. 2) employed consisted of the first 21 exercises of the 26-exercise sequence developed by Hallal et al. (2010). Table 1 shows schematically the 21 exercises in the sequence in which they were performed during the eight weeks of training.

As noted above, the OPG performed the proposed exercises with the vibratory pole oscillating, while the NPG performed the same exercises without oscillation of the pole (Fig. 3).

The balance exercises were performed in order of increasing level of difficulty during the training sessions, which were composed of three or four balance exercises. The volunteers were required to execute each exercise five times, maintaining it for $15 \mathrm{~s}$, with a one-minute gap between repetitions (Hallal et al., 2010). In each session, one exercise from the previous session was repeated (the one with the highest difficulty level) and two new exercises were introduced. The exercises were performed as a group and, if one of the volunteers could not maintain an exercise for $15 \mathrm{~s}$, it was repeated by all the volunteers until all of them succeeded in executing it. During the eight weeks of follow up the volunteers of both groups were instructed to maintain their levels of physical activity similar to before the beginning of balance training. 


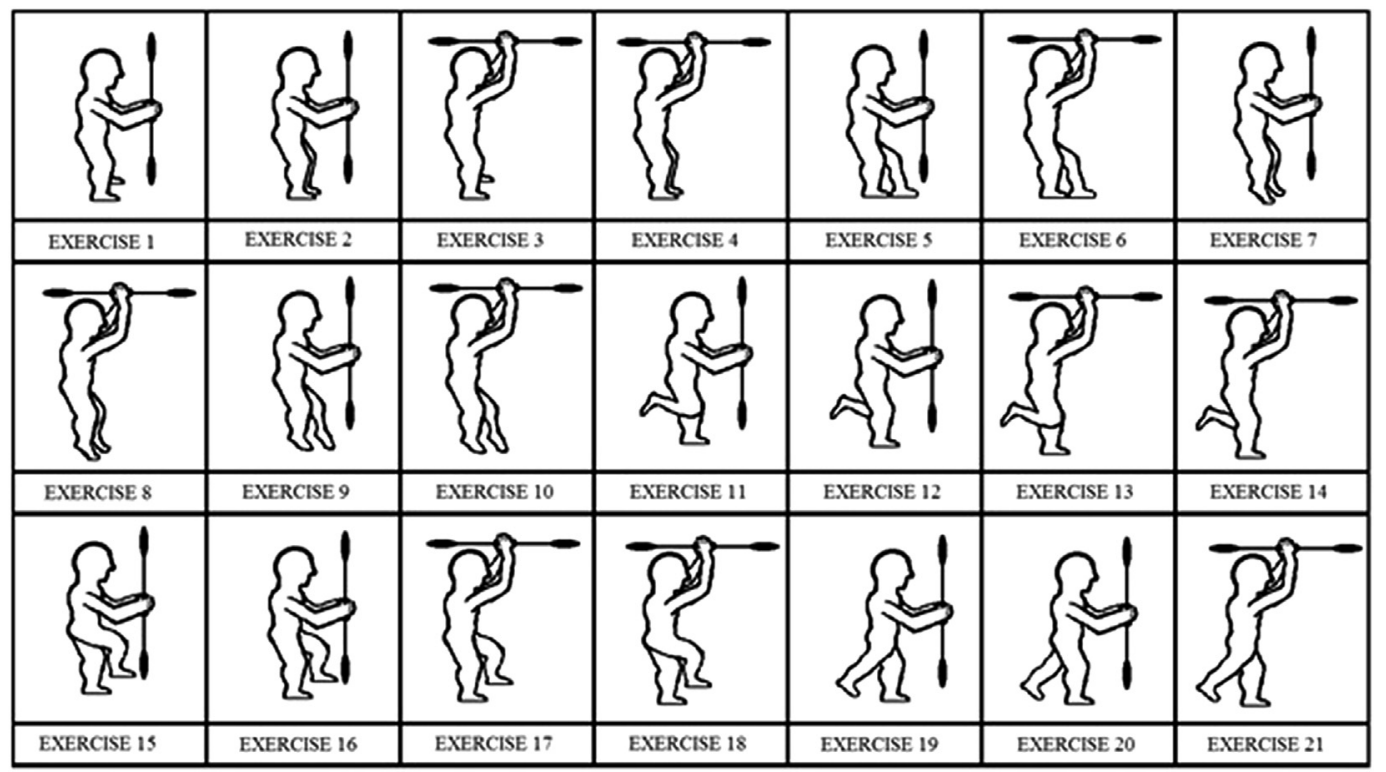

Figure 2 Schematic illustration of the 21 exercises of the balance training protocol. Modified from Hallal et al.

\section{Statistical analyses}

The Statistical Package PASW 18.0 (SPSS Inc.) was used for the statistical analyses. After verifying the normality of the data by means of the Shapiro Wilk test, the ANOVA two-way test with repeated measures was used, followed by the Bonferroni post-hoc test in order to verify the effect of training on the functional balance. The MANOVA test followed by the Bonferroni post-hoc test was also used to compare the sample characterization. The significance level adopted for data interpretation was $5 \%(p<.05)$.

\section{Results}

Table 2 summarizes the characteristics of the 29 elderly women who effectively concluded the study. No significant differences were found between the groups $(p>.05)$, therefore indicating that the groups were homogeneous with relation to age, weight, height, Body Mass Index (BMI), cognitive functions and bone mineral density.

According to the IPAQ level, $78.6 \%$ of the OPG volunteers were classified as physically active and $21.4 \%$ as highly

Table 1 Sequence of the 21 exercises performed during the eight weeks of training.

\begin{tabular}{ll}
\hline Week & Exercises performed \\
\hline 1 & $1,2,3 \& 4$ \\
2 & $4,5,6 \& 7$ \\
3 & $7,8,9 \& 10$ \\
4 & $10,11,12 \& 13$ \\
5 & $13,14 \& 15$ \\
6 & $15,16 \& 17$ \\
7 & $17,18 \& 19$ \\
8 & $19,20 \& 21$ \\
\hline
\end{tabular}

active; in the NPG, $73.3 \%$ of the volunteers were classified as active and $26.7 \%$, as highly active.

Fig. 4 shows the Berg Balance Scale data for both groups for the three different evaluations performed. The NPG presented improvements in balance upon comparing the values observed in Pre-Training $(53.47 \pm 2.07)$ with those of Post-Training $(55.33 \pm .98)(\mathrm{p}=.018)$ and Post-Follow-Up $(55.5 \pm 1.05)(p=.007)$. On the other hand, the OPG presented near-significant difference between Pre-Training $(53.14 \pm 2.14)$ and Post-Training $(54.7 \pm 1.44)(p=.051)$ values and an improvement in balance upon comparison of the values achieved in the Pre-Training with the PostFollow-Up $(54.92 \pm 1.32)(p=.038)$. Both groups showed no significant difference between Post-Training and PostFollow-Up ( $p=.999)$. There were also no significant differences in the intergroup comparisons $(p>.05)$.

\section{Discussion}

The primary goal of the present study was to verify the effects of an eight-week balance training program, with and without oscillation of a vibratory pole, on the functional equilibrium of elderly women with osteoporosis. Vibration as an auxiliary tool for enhancing physical qualities such as muscle strength, resistance and balance has been the focus of several recent investigations (Delecluse et al., 2003; Bogaerts et al., 2007, 29. Lister et al., 2007; Moreside et al., 2007). Several studies have evaluated the effects of whole-body vibration on women with osteoporosis (Torvinen et al 2002, Pang, 2010; Stengel et al., 2011; Armbrecht et al., 2010). For example, Gusi et al. (2006) found that, after an eight-month training program on a vibratory platform with three weekly sessions, there was a $29 \%$ increase in postural balance and a $4.3 \%$ increase in bone mineral density in the femoral neck of the participating volunteers. 


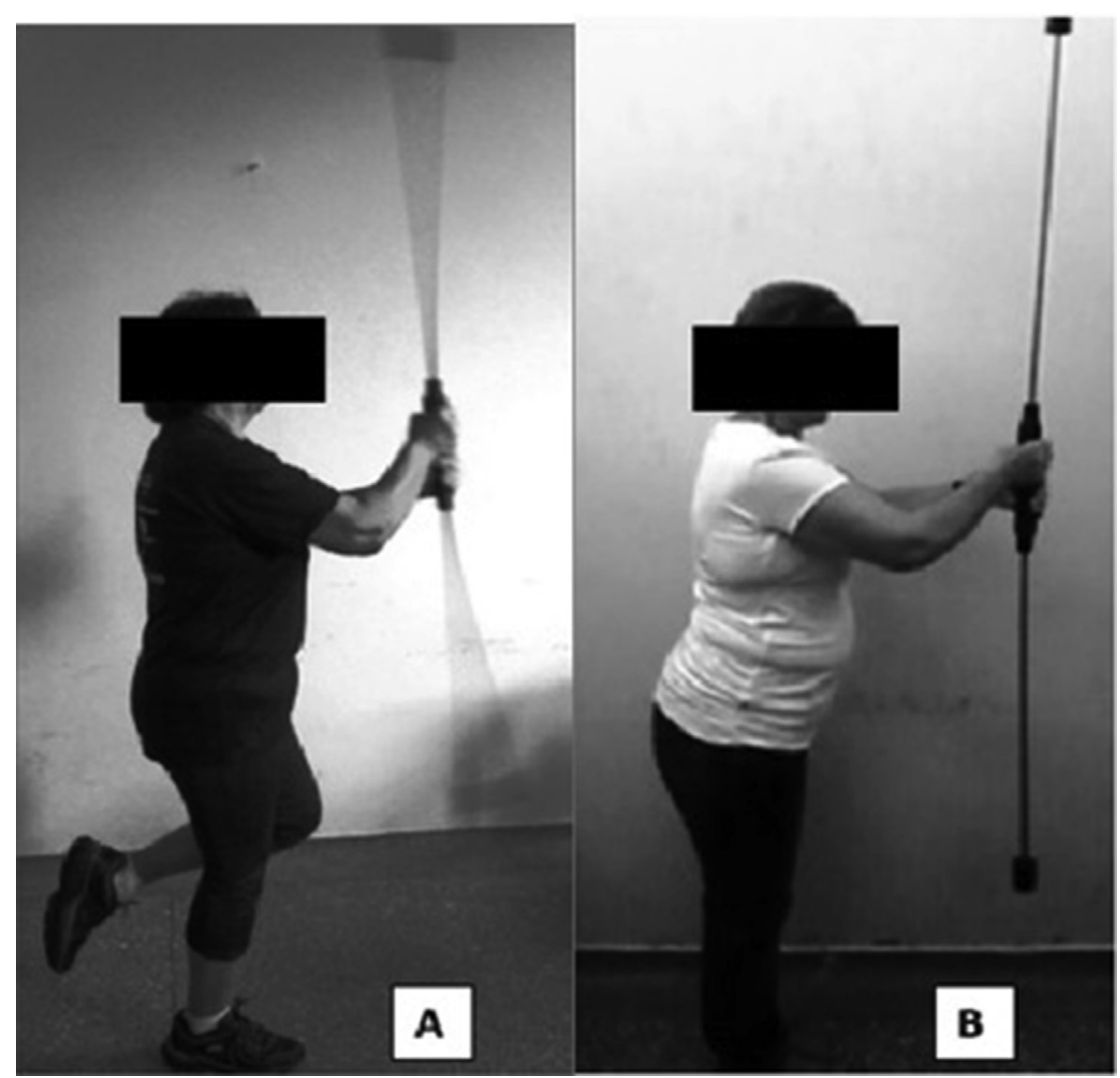

Figure 3 (A) An OPG volunteer performing exercise 12 of the balance training protocol with oscillation of the viratory pole; (B) An NPG volunteer performing exercise 2 of the balance training protocol without oscillation of the pole.

After eight weeks of balance training, the NPG presented significant improvement in functional equilibrium. The fact that improvement in the OPG immediately upon finishing the training was only near-significant statistically might be the result of the dual task demanded of this group of volunteers during the training. Thus, besides maintaining the requisite posture as in the NPG, the OPG also had to employ the oscillation of the vibratory pole. During the execution of dual tasks, a high level of information processing is required and the performance of one or the other task may be partially compromised (Teixeira and Alouche, 2007). The dual task demanded during the training might therefore be responsible for the result observed for the OPG. In addition, an elderly population might present a

Table 2 Characterization of the two experimental groups.

\begin{tabular}{lcccc}
\hline Variables & OPG $(\mathrm{n}=14)$ & & NPG $(\mathrm{n}=15)$ & $\mathrm{p}$ value \\
\cline { 2 - 2 } \cline { 5 - 5 } & Median $\pm \mathrm{SD}$ & & Median $\pm \mathrm{SD}$ & \\
\hline Age (years) & $69.6 \pm 5.8$ & & $70.9 \pm 7.4$ & .589 \\
Body Mass $(\mathrm{kg})$ & $71.2 \pm 17.7$ & & $67.8 \pm 9.5$ & .550 \\
Height $(\mathrm{m})$ & $1.54 \pm .06$ & & $1.54 \pm .09$ & .893 \\
IMC $\left(\mathrm{kg} / \mathrm{m}^{2}\right)$ & $31.5 \pm 11.6$ & $29.0 \pm 3.5$ & .441 \\
MEEM & $26.6 \pm 3.5$ & & $28.3 \pm 5.0$ & .285 \\
Spine T-Score & $-2.9 \pm .3$ & $-3.0 \pm .4$ & .342 \\
\hline
\end{tabular}

OPG: Oscillating Pole Group; NPG: Non-Oscillating Pole Group; SD: Standard Deviation; BMI: Body Mass Index; MEMS: Mini Exam of Mental State; kg: kilogram; m: meter. decreased capacity for executing the dual task due to distractions and low motivation with only partial use of the capacity of their Central Nervous System (Gehring et al., 2009). As the simultaneous task processing becomes more complex, this might have caused a deficit in the postural stability, thus influencing equilibrium, which possibly was reflected in the BBS values obtained.

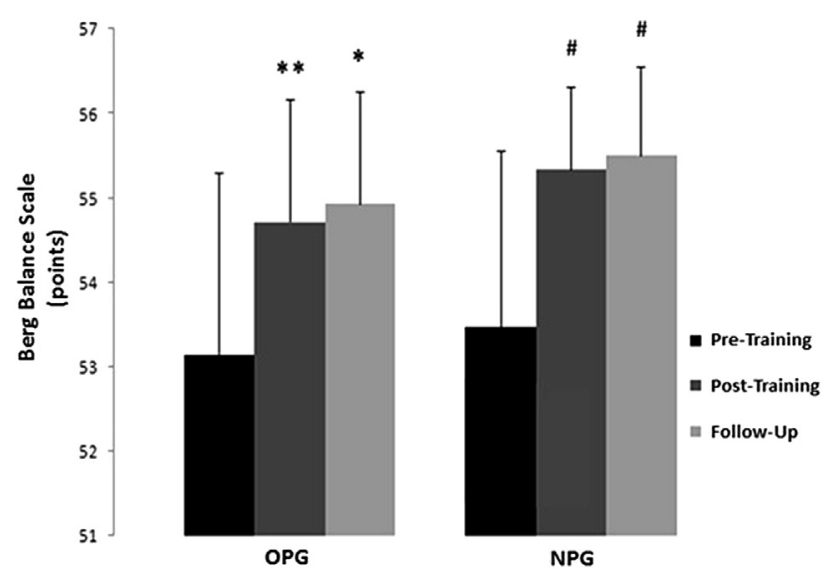

Figure 4 BBS values exhibited by the volunteers in the PreTraining, Post-Training and Post-Follow-Up evaluations. OPG: Oscillating Pole Group, NPG: Non-Oscillating Pole Group. * $(p<.05)$ significant improvement when compared to the OPG Pre-Training values \# $(p<.05)$ significant improvement when compared to NPG Pre-Training Values. ${ }^{* *}$ Near-significant difference $(p=.051)$. 
It should be noted that both of the groups presented very good performance on the BBS before the beginning of the training protocol performance, i.e., $53.1 \pm 2.1$ points for the OPG and $53.5 \pm 2.1$ points for the NPG, indicating that, on the whole, the volunteers already had relatively good equilibrium. This fact might have had an influence on the improvement in equilibrium achieved by the volunteers after training, since a lower initial test performance might have permitted a greater variation between the initial and final scores on the BBS. Alternatively, the frequency of the oscillation of the vibrating pole $(5 \mathrm{~Hz})$ may have been too low to stimulate the muscle tissue and the appropriate neuroreceptors adequately to cause an improvement in balance different from that observed for the NPG. A somewhat higher frequency, closer to that employed in the vibratory platform studies $(20-35 \mathrm{~Hz})$, might have resulted in a greater difference between OPG and NPG (Stengel et al., 2011; Gusi et al., 2006).

In the present study, a significant improvement in balance was observed at the end of the Follow-Up period for both the Oscillating Pole Group and the NPG. Although the pole did not oscillate in the exercises of the NPG, the elderly women in the NPG were submitted to the same 21 balance training exercises, which required them to maintain and control their posture. Thus, it would appear that the balance training protocol per se was the primary cause of the improvement in the functional equilibrium of women with osteoporosis, i.e., the postures adopted by the volunteers during the training were the main factor responsible for the improvement in equilibrium within this population with little or no influence of oscillation of the vibratory pole.

\section{Conclusion}

The balance training applied without oscillation of the vibratory pole promoted an improvement in the functional equilibrium of the elderly volunteers and they maintained these characteristics for at least eight weeks after the training period. The same training applied with oscillation of the vibratory pole was also able to cause a statistically significant improvement in the functional equilibrium after the Follow- Up period. At the end of the training period, Hallal et al. (2010) also found an improvement in the functional equilibrium of elderly women in a Training Group that performed exercises with the oscillating vibratory pole, as well as in a Control Group that performed exercises without oscillation of the pole. The present study not only confirmed the beneficial effect of their balance training protocol, but also showed, via the Follow-Up, that an eightweek training program can lead to medium-term persistence of the improvement in the equilibrium of physicallyactive elderly women with osteoporosis.

\section{Acknowledgment}

This study was supported financially by FAPESP - Foundation for Support of Research of the State of São Paulo. Grant number: 2010/8454-0.

\section{References}

Almeida, O.P., Crocco, E.I., 2000. Percepção dos déficits cognitivos e alterações do comportamento em pacientes com doença de Alzheimer. Arq. Neuropsiquiatr. 58 (2A), 292-299.

Anders, C., Wenzel, B., Scholle, H.C., 2008. Cyclic upper body perturbations caused by a flexible pole: influence of oscillation frequency and direction on trunk muscle co-ordination. J. Back Musculoskelet. Rehabil. 20, 167-175.

Armbrecht, G., Belavý, D.L., Gast, U., Bongrazio, M., Touby, F., Beller, G., Roth, H.J., Perschel, F.H., Rittweger, J., Felsenberg, D., 2010. Resistive vibration exercise attenuates bone and muscle atrophy in 56 days of bed rest: biochemical markers of bone metabolism. Osteoporos Int. 21, 597-607.

Arnold, C.M., Busch, A.J., Schachter, C.L., Harrison, E.L., Olszynski, W.P., 2008. A randomized clinical trial of aquatic versus land exercise to improve balance, function, and quality of life in older women with osteoporosis. Physiother. Can. 60, 296-306.

Benedetti, T.B., Mazo, G.Z., Barros, M.V.G., 2004. Aplicação do questionário internacional de atividades físicas para avaliação do nível de atividades físicas de mulheres idosas: validade concorrente e reprodutibilidade teste-reteste. Rev. Bras. Ciência Mov. 12 (1), 25-34 (Brazil).

Bogaerts, A., Verschueren, S., Delecluse, C., Claessens, A.L., Boonen, S., 2007. Effects of whole body vibration training on postural control in older individuals: a 1 year randomized controllers trial. Gait Posture 26, 309-316.

Cormie, P., Deane, R.S., Triplett, T., Mcbride, J.M., 2006. Acute effects of whole-body vibration on muscle activity, strength, and power. J. Strength Cond. Res. 20 (2), 257-261.

Costa, E.L., Bastos Filho, P.S.C., Moura, M.S., Sousa, T.S., Lemos, A., Pedrosa, M.A.C., 2012. Efeitos de um programa de exercícios em grupo sobre a força de preensão manual em idosas com baixa massa óssea. Arq. Bras. Endocrinol. Metabol. 56 (5), 313-318.

Craig, C.L., Marshall, A.L., Sjostrom, M., Bauman, A.E., Booth, M.L., Ainsworth, B.E., et al., 2003. The international physical activity questionnaire - IPAQ: 12- country reliability and validity. Med. Sci. Sports Exerc. 35 (8), 1381-1395.

Delecluse, C., Roelants, M., Verschueren, S., 2003. Strength increase after whole-body vibration compared with resistance training. Med. Sci. Sports Exerc. 35 (6), 1033-1041.

Faria, J.C., Machala, C.C., Dias, R.C., Dias, J.M.D., 2003. Importância do treinamento de força na reabilitação da função muscular, equilíbrio e mobilidade de idosos. Acta Fisiatr. 10 (3), 133-137 (Brazil).

Gehring, P.R., Bertolassi, M.A., Nunes, M.E.S., Basso, L., Meira Júnior, C.M., Santos, S., 2009. Desempenho de idosos em uma tarefa motora de demanda dupla de controle. Rev. Bras. Educ. Física Esporte 23 (3), 211-220 (Brazil).

Gonçalves, M., Marques, N.R., Hallal, C.Z., Dieën, J.H.V., 2011. Electromyographic activity of trunk muscles during exercises with flexible and non-flexible poles. J. Back Musculoskelet. Rehabil. 24, 209-214.

Gusi, N., Raimundo, A., Leal, A., 2006. Low-frequency vibratory exercise reduces the risk of bone fracture more than walking: a randomized controlled trial. BMC Musculoskelet. Disord. 7, $1-8$.

Hallal, C.Z., Marques, N.R., Gonçalves, M., 2010. Avaliação do risco de quedas de idosas ativas submetidas a treinamento de equilíbrio com haste vibratória. Ter. Man. 8, 192-197 (Brazil).

Lirani-Galvão, A.P.R., Lazaretti-Castro, M., 2010. Physical approach for prevention and treatment of osteoporosis. Arq. Bras. Endocrinol. Metabol. 54 (2), 171-178.

Lister, J.L., Rossi, G.D., Stoutenberg, M., Adams, J.B., Tobkin, S., Signorile, J., 2007. Scapular stabilizer actitity during 
Bodyblade $^{\circledR}$, cuff weigths, and Thera-band ${ }^{\circledR}$ use. J. Sport Rehabil. 16, 50-57.

Madureira, M.M., Takayama, L., Gallinaro, A.L., Caparbo, V.F., Costa, R.A., Pereira, R.M.R., 2007. Balance training program is highly effective in improving functional status and reducing the risk of falls in elderly women with osteoporosis: a randomized controlled trial. Osteoporos Int. 18, 419-425.

Meneses, S.R.F., Burke, T.N., Marques, A.P., 2012. Equilíbrio, controle postural e força muscular em idosas osteoporóticas com e sem quedas. Fisioter. Pesqui. 19 (1), 26-31 (Brazil).

Meuleman, J.R., Brechue, W.F., Kubilis, P.S., Lowenthal, D.T., 2000. Exercise training in the debilitates aged: strength and functional outcomes. Arch. Phys. Med. Rehabil. 81 (3), 12-18.

Mileva, K.N., Kadr, M., Amin, N., Bowtell, J.L., 2010. Cute effects of flexi-bar vs. Sham-bar exercise on muscle electromyography activity and performance. J. Strength Cond. Res. 24 (3), 737-748.

Moreside, I.M., Garcia, F.V., Mcglil, S.M., 2007. Trunk muscle activation patterns, lumbar compressive forces, and spine stability when using the Bodyblade. Phys. Ther. 87 (3), 153-164.

Myiamoto, S.T., Lombardi, J.I., Berg, K.O., Ramos, L.R., Natour, J., 2004. Brazilian version of the Berg Balance Scale. Braz. J. Med. Biol. Res. 37 (8), 1411-1421.

National Institutes of Health. Consensus Development Panel on Osteoporosis Prevention, Diagnosis, and Therapy, 2001. Osteoporosis prevention, diagnosis, and therapy. J. Am. Med. Assoc. 285, 785-795.

Navega, M.T., Faganello, F.R., Oishi, J., 2008. Comparação da Qualidade de Vida entre mulheres com osteoporose acometidas ou não por fratura de quadril. Fisioter. Mov. 21 (3), 101-108.

Pang, M.Y.C., 2010. Whole body vibration therapy in fracture prevention among adults with chronic disease. World J. Osteoporos 18 (1), 20-25.

Pinheiro, M.M., Ciconelli, R.M., Jacques, N.O., Genaro, P.S., Martini, L.A., Ferraz, M.B., 2010. 0 impacto da osteoporose no Brasil: dados regionais das fraturas em homens e mulheres adultos - the Brazilian Osteoporosis Study (BRAZOS). Rev. Bras. Reumatol. 50 (2), 113-127. Brazil.
Randell, A.G., Nguyen, T.V., Bhalerao, N., 2000. Deterioration in quality of life following hip fracture: a prospective study. Osteoporos. Int. 11 (5), 460-466.

Rees, S.S., Murphy, A.J., Watsford, M.L., 2008. Effects of wholebody vibration exercise on lower-extremity muscle strength and power in an older population: a randomized clinical trial. Phys. Ther. 88 (4), 462-470.

Roelants, M., Verschueren, S.M.P., Delecluse, C., Levin, O., Stijnen, V., 2006. Whole-body-vibration induced increased in leg muscle activity during different squat exercises. J. Strength Cond. Res. 20 (1), 124-129.

Schröder, G., Knauerhase, A., Kundt, G., Schober, H.C., 2012. Effects of physical therapy on quality of life in osteoporosis patients - a randomized clinical trial. Health Qual. Life Outcomes 10, 101-108.

Shumway-Cook, A.S., Woolacott, M.H., 2003. Controle Motor: teoria e aplicação prática, second ed. Manole, Barueri, SP.

Souza, S.P.M.C., Morais, F.E., Santos, E.V., Silva, M.L., MartinezHuitle, C.A., Fernandes, N.S., 2012. Determinação do teor de cálcio em comprimido à base de lactato de cálcio utilizado no tratamento da osteoporose. Quimica Nova 35 (7), 1355-1359 (Brazil).

Stengel, S.V., Kemmler, W., Engelke, K., Kalender, W.A., 2011. Effects of whole body vibration on bone mineral density and falls: results of the randomized controlled ELVIS study with postmenopausal women. Osteoporos. Int. 22, 317-325.

Teixeira, N.B., Alouche, S.R., 2007. O desempenho da Dupla tarefa na Doença de Parkinson. Braz. J. Physio Ther. 11 (2), 127-132.

Torvinen, S., Kannus, P., Sievanen, H., Jarvinen, T.A.H., Pasanen, M., Kontulainem, S., 2002. Effect of four-month vertical whole body vibration on performance and balance. Med. Sci. Sports Exerc. 39 (2), 1528-1532.

Verschueren, S.M.P., Roclants, M., Delecluse, C., Swinnen, S., Vanderschueren, D., Boonen, S., 2004. Effect of 6-month whole body vibration training on hip density, muscle strength, and postural control in postmenopausal women: a randomized controlled pilot study. J. Bone Mineral Res. 19 (3), 352-359. 